Gut, 1960, 1, 337.

\title{
SOME FACTORS IN THE ASSESSMENT OF GASTRIC ANTISECRETORY DRUGS BY A SAMPLING TECHNIQUE*
}

\author{
BY \\ J. P. BINGLE and J. E. LENNARD-JONES
}

\begin{abstract}
From the General Infirmary at Leeds, University College Hospital, and the Medical Research Council Department of Clinical Research, University College Hospital, London
\end{abstract}

Samples of gastric contents from patients with duodenal ulcer were more often highly acid when they drank $120 \mathrm{ml}$. of milk-cream mixture every hour than when they ate a bland diet. The volume of the drinks and the timing of the samples determined this apparent difference. Long-acting propantheline bromide reduced gastric acidity a little when the patients ate the diet and more when they took the drinks of milk-cream alone. It is concluded that the clinical usefulness of gastric antisecretory drugs can only be assessed under the actual conditions of use.

In 1958, Kasich and Argyros showed that a longacting form of propantheline bromide, given in a dose of $120 \mathrm{mg}$. twice daily to patients with duodenal ulcer, often reduced the acidity of their gastric contents to $p \mathrm{H} 3$ or 4 throughout the 24 hours. So as to control the variables of their experiment as closely as possible they gave their patients hourly drinks of a milk-cream mixture, during waking hours, without other food. When, in a pilot study, we repeated their observations but gave our patients a bland "gastric type" diet instead of the milk-cream drinks, we found that the drug produced no definite reduction in acidity. It seemed possible that our results differed from theirs because our patients took food.

This difference led to a study of the factors involved when gastric antisecretory drugs are assessed by a sampling technique. The following observations show that the acidity of any gastric sample depends on the interval since food was taken and on the amount and type of food. A comparison of the effect of propantheline $\dagger$ on a day when patients took hourly drinks of milkcream with that on a day when they took a standard bland diet confirmed that the effect of the drug was less when patients were taking the diet. Observations have also been made which indicate that propantheline affects the acidity of gastric samples more by re-

\footnotetext{
* This paper was read at the annual meeting of the British Society of Gastroenterology in London on November 4, 1960.

†ro-Banthine (prolonged action) kindly supplied by G. D. Searle and Co.
}

ducing gastric secretion than by slowing the rate at which food leaves the stomach.

\section{METHOD}

All patients studied had a typical, radiologically proven uncomplicated duodenal ulcer. They were encouraged to live as normal lives as possible in the ward. No drugs were given except for a hypnotic at night and propantheline. At the start of each experiment, a fine nasogastric tube was placed fluoroscopically so that the holes for aspiration lay over the vertebral column, in the likely position of the gastric antrum. At intervals of either 10 minutes or of one hour during the various experiments, $5-10 \mathrm{ml}$. samples of gastric contents were withdrawn. These were stored in a refrigerator until the $p \mathrm{H}$ of unfiltered specimens was measured with a sealed glass electrode. We calibrated the electrode between $p \mathrm{H} 1$ and 2 , as well as at $p \mathrm{H} 4$ and 9 , since this was the range in which most of our observations were made.

In the main experiment to compare the effects of the drug when patients took two different diets, 12 patients were each studied for two periods of $\mathbf{4 8}$ hours. During one of these periods $120 \mathrm{mg}$. of long-acting propantheline was given by mouth every 12 hours. Each patient given this dose of propantheline was given smaller doses beforehand to find out whether this large dose could be tolerated. The conditions were changed on each of the four days as follows:

A: Hourly drinks of $120 \mathrm{ml}$. of a mixture of 3 parts milk and 1 part light cream taken on the hour from 8 a.m. to 9 p.m.

B: A standard bland diet (see appendix).

C: Hourly milk-cream drinks, propantheline at 8 a.m. and 8 p.m.

D: Standard diet, propantheline at 8 a.m. and 8 p.m. 
The order of these different conditions was varied from patient to patient in a latin-square pattern:

\begin{tabular}{l|c|c||c|c}
\hline & 1st Day & 2nd Day & 3rd Day & 4th Day \\
\cline { 2 - 5 } Patient 1 & A & B & C & D \\
Patient 2 & C & D & A & B \\
Patient 3 & B & A & D & C \\
Patient 4 & D & C & B & A \\
\hline
\end{tabular}

This sequence was repeated three times during the investigation of the 12 patients; the double line separates the 48-hour periods. Observations began at 8 a.m. and continued until 7 a.m. the next morning. Samples were withdrawn every hour on the hour and immediately before doses of propantheline, drinks of milk-cream, or meals.

When the effect of giving different volumes of milkcream or the mode of action of propantheline was studied in short experiments, observations were made in the morning, the patients having fasted since the previous evening. The tube was placed fluoroscopically as already described and, before observations were made, the stomach was emptied completely while the patient adopted different postures.

\section{RESULTS}

The results of the 24-hour studies are shown in Figs. 1, 2, and 3. In each figure the results for all 12 patients are grouped together. Each section of the histograms in Figs. 1 and 3 compares the total number of samples in a particular $p \mathrm{H}$ range under two different conditions. Fig. 2 shows the mean acidity, calculated on an arithmetic scale, at each hour of the day during the test periods.

\section{The Effect of Food on the $p H$ of Gastric SAMPLES}

TYPE OF FOOD.-There were fewer very acid

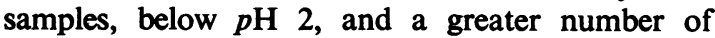
samples, less acid than $p \mathrm{H} 2.5$, when the patients took a diet than when they took the hourly drinks of milk-cream (Fig. 1a). These differences are statistically significant. The reason for this finding is seen in Fig. 2(a), which shows that the samples were consistently highly acid when the hourly drinks were taken, without the troughs of low acidity which occurred after meals. The differences at 9 a.m., 1 and 2 p.m., and 7 and 8 p.m. (one to two hours after main meals) are statistically significant $(P=<0.05)$.

AMOUNT OF Food.-This was most conveniently studied using a liquid food, in this case different volumes of milk-cream mixture. Fig. 4 shows that the acidity of the gastric contents fell after each drink, and fell to a lower level with a longer period of low acidity, as larger volumes were taken.

Buffering Power OF FoOD.-Fig. 5 shows the buffering power in vitro of the milk-cream mixture against histamine-stimulated gastric juice compared

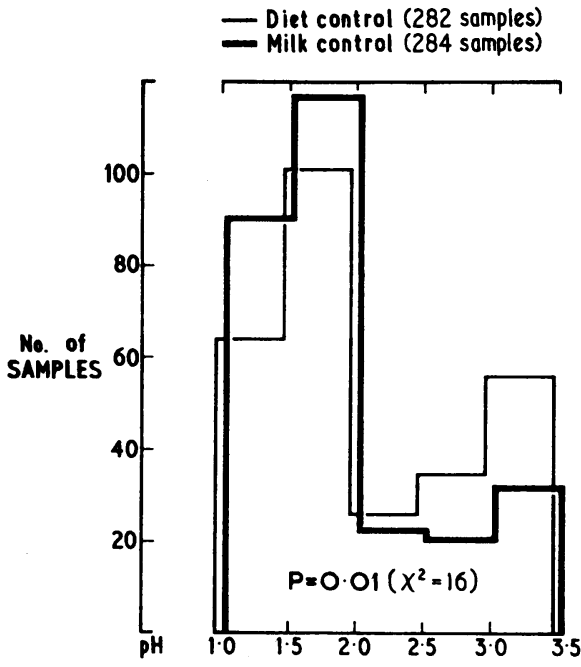

(a)

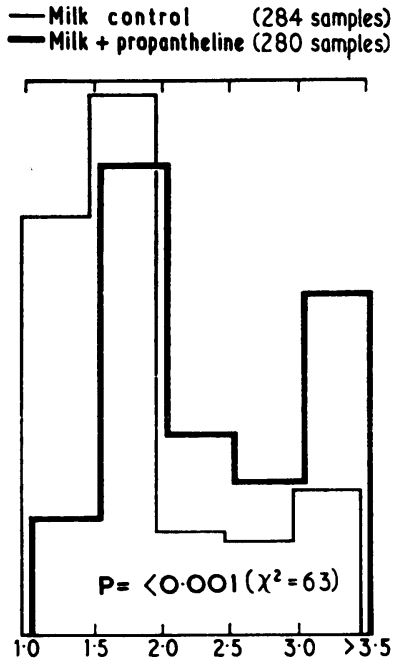

(b)

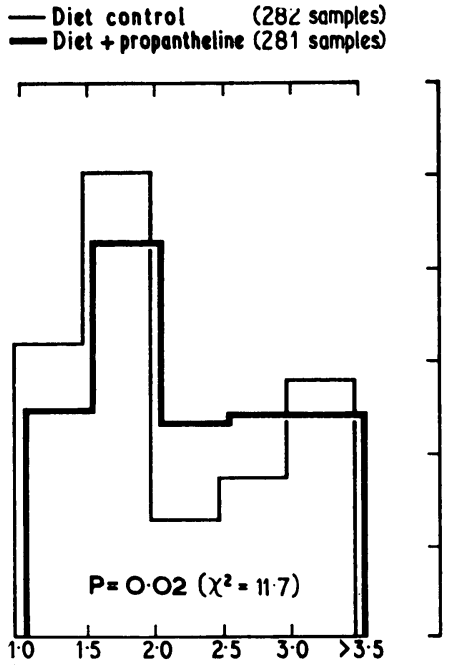

(c)

FIG. 1.-The number of samples in different $\mathrm{pH}$ ranges under different conditions. Differences between the distribution of the samples have been assessed by the $\chi^{2}$ test $(n=4)$. Three of the results are shown. There is also a significant difference $\left(\chi^{2}=16 \cdot 8, P=0.01\right)$ between the distributions when propantheline was taken with diet and when propantheline was taken with hourly drinks of milk-cream. 


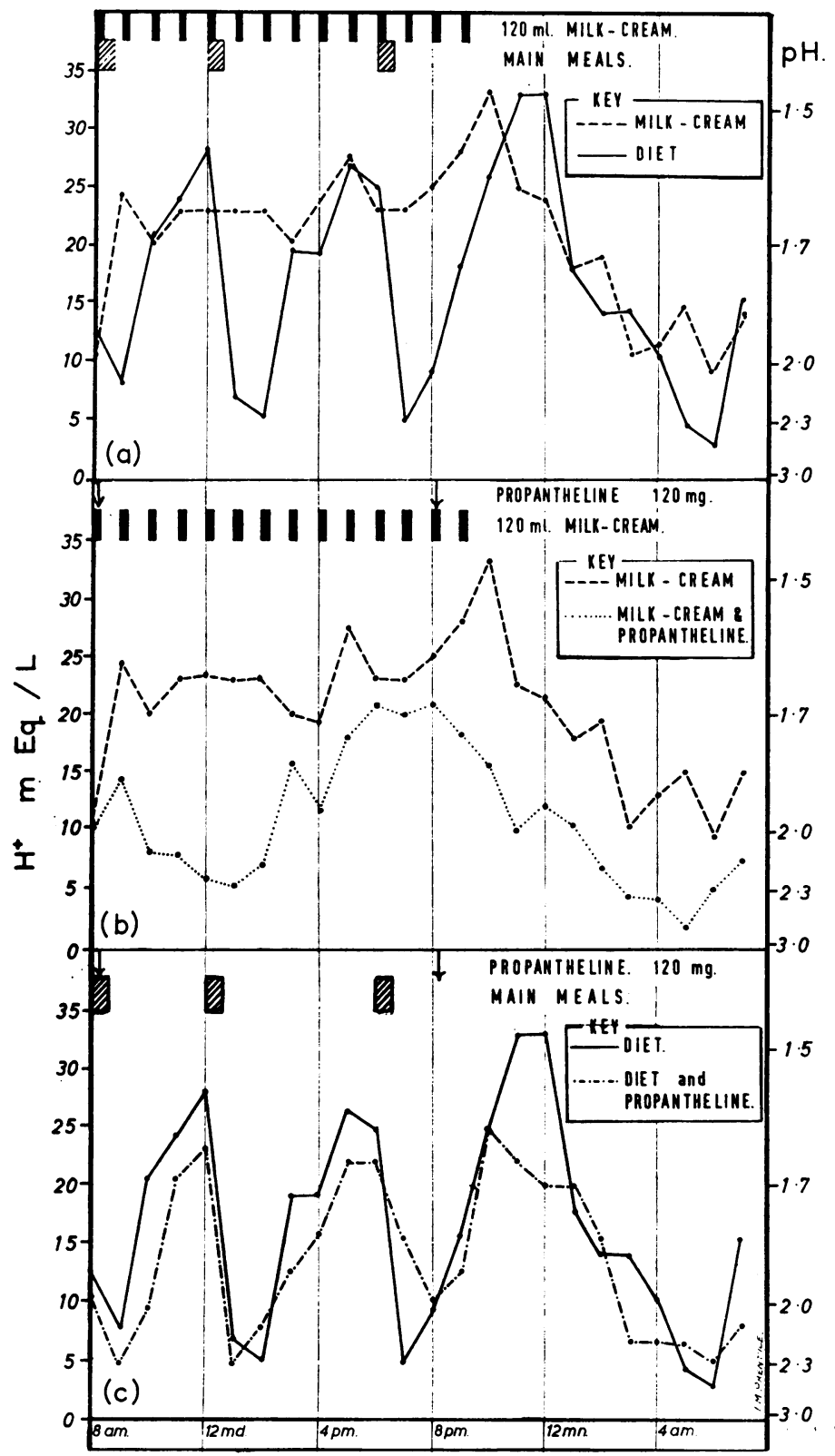

FIG. 2.-The mean acidity at each hour of the day under different conditions.

with the effect of simple dilution of the juice with water. The addition of milk-cream to a sample of gastric juice of equal volume reduced its acidity tenfold ( $p \mathrm{H} 1$ to $p \mathrm{H} 2)$. Skimmed milk and light cream each yielded almost identical curves.

Timing of SAmples AfTer Food.-Fig. 4 shows that the $p \mathrm{H}$ of samples withdrawn half an hour after a drink was different from the $p \mathrm{H}$ of samples withdrawn one hour after a drink. Before starting these experiments the stomach was completely emptied. Other experiments have shown that the fall in acidity is of shorter duration when the stomach is not emptied beforehand. Fig. 2(a) shows that the 


\section{SIDE EFFECTS (6 patients)}

NO SIDE EFFECTS (6 patients)

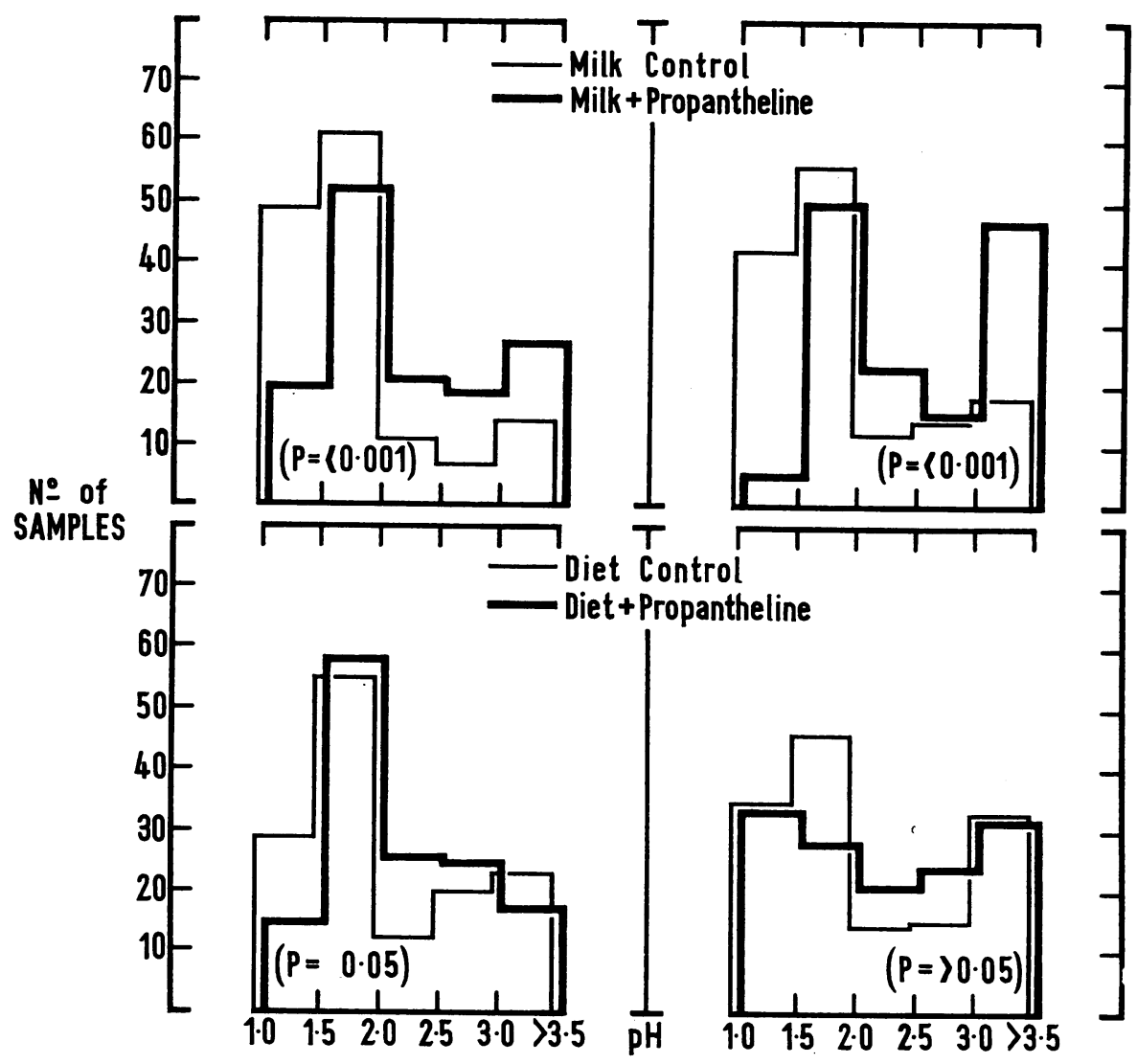

Fig. 3.-The distribution of samples in different $\mathrm{pH}$ ranges among patients who experienced side-effects from propantheline compared with the distribution among those who experienced no sidz-effects.

acidity of samples withdrawn after a meal depends on the length of time since the meal was taken.

\section{The Effect of Long-acting Propantheline Bromide on $p H$ of Gastric Samples}

With MilK-CREAm DrinKs.-After propantheline there were significantly fewer very acid samples below $p \mathrm{H} 2$ and a greater number of samples which were less acid than $p \mathrm{H} 2.0$ (Fig. 1(b)). This finding is illustrated in Fig. 2(b) which shows that the mean acidity of the samples was less after propantheline at every hour of the day. The differences between values from 9 a.m. to 2 p.m. (three to nine hours after the first dose of the drug) and 10 p.m. to 12 a.m. (four hours after the second dose) are statistically significant $(P=<0.05)$.
WiTh DiET.-After the drug there were again significantly fewer very acid samples and a greater proportion of the less acid samples (Fig. 1(c)) than on the control day, but the differences were not so great as when milk-cream drinks were taken (Fig. 1(b) ). The curves of mean acidity at each hour of the day (Fig. 2(c)) suggest that the peak acidities before meals and at night may have been reduced by propantheline, but the differences are not statistically significant.

A direct comparison between the two days when propantheline was given shows that there was a significantly $(P=0.01)$ smaller proportion of samples more acid than $p \mathrm{H} 2$ and a greater proportion of less acid samples when the milk-cream drinks were taken than when the diet was taken (Fig. 1(b) and (c) ). 

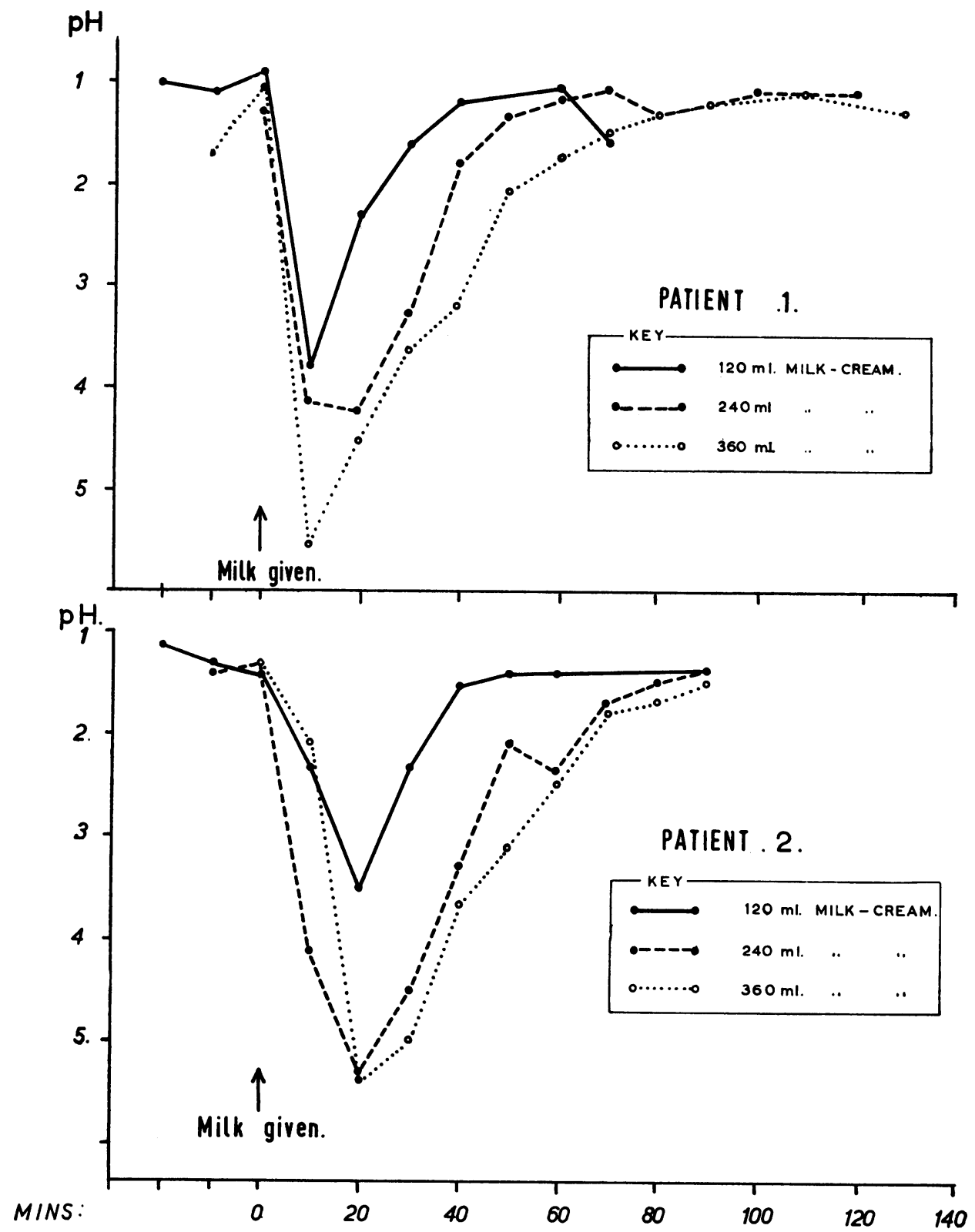

FIG. 4.-The $\mathrm{pH}$ of gastric samples taken at 10-minute intervals after drinking different volumes of milk-cream.

Effective Dose of Propantheline.-During studies of the effect of drugs, including long-acting propantheline, on the secretion of acid under basal conditions, Sun, Shay, and Ciminera (1955) showed that to suppress secretion entirely the drugs had to be given in the maximal dose, "the optimal effective dose", that produced dryness of the mouth without other uncomfortable symptoms of parasympathetic inhibition.* Six of our patients experienced side-effects from the drug (Table I) and

* These authors found the "optimal effective dose" of long-acting propantheline bromide to be $30 \mathrm{mg}, 60 \mathrm{mg}$, $180 \mathrm{mg}$., and $180 \mathrm{mg}$. in four patients. We chose $120 \mathrm{mg}$. as the standard dose so that our results should be comparable to those of Kasich and Argyros (1958). 


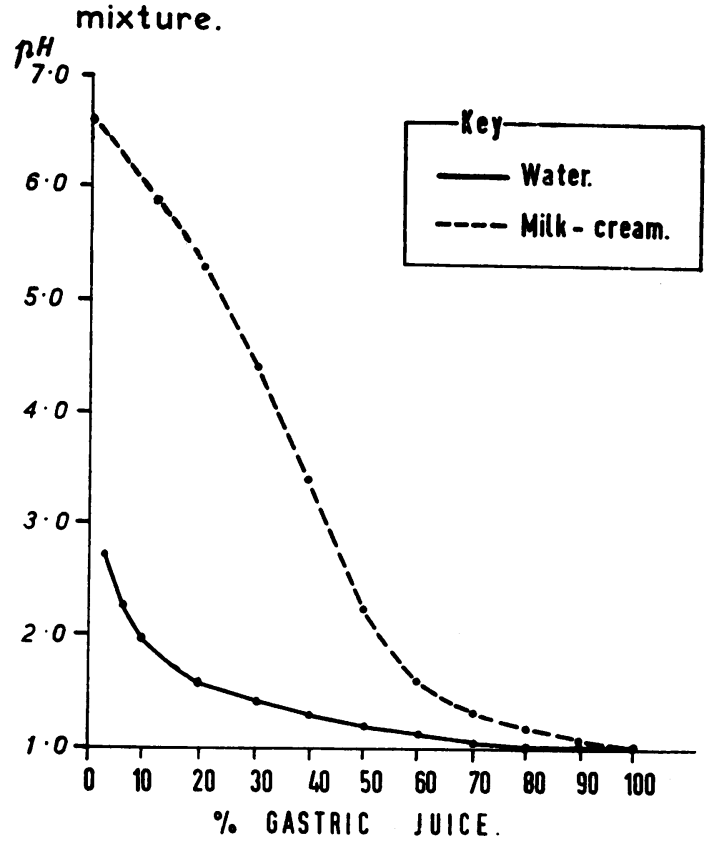

Fig. 5.-The $\mathrm{pH}$ of histamine-stimulated gastric juice $(125 \mathrm{mN})$ mixed in different proportions with water or milk-cream.
TABLE I

SIDE-EFFECTS FROM LONG-ACTING PROPANTHELINE BROMIDE

\begin{tabular}{|c|c|c|}
\hline \multirow{2}{*}{ Patient } & \multicolumn{2}{|c|}{ Side-effects from Propantheline } \\
\hline & Day 1 & Day 2 \\
\hline 3 & Dry mouth & $\begin{array}{l}\text { Dry mouth, hesitancy of } \\
\text { micturition }\end{array}$ \\
\hline 6 & & $\begin{array}{l}\text { Slight hesitancy of } \\
\text { micturition }\end{array}$ \\
\hline 7 & Slight blurring of vision & Very dry moutb, hesi- \\
\hline 8 & None & $\begin{array}{l}\text { Blurred vision, dry } \\
\text { mouth, hesitancy of } \\
\text { micturition }\end{array}$ \\
\hline 10 & $\begin{array}{l}\text { Dry mouth, blurred } \\
\text { vision }\end{array}$ & $\begin{array}{l}\text { Dry mouth, blurred } \\
\text { vision }\end{array}$ \\
\hline 12 & $\begin{array}{l}\text { Dry mouth, blurred } \\
\text { vision }\end{array}$ & $\begin{array}{l}\text { Dry mouth, blurred } \\
\text { vision }\end{array}$ \\
\hline
\end{tabular}

six experienced none. The results in these two groups of six patients are shown in Fig. 3. On the day when milk-cream was taken, the effect of propantheline was apparently equal whether sideeffects occurred or not. On the day of the diet, propantheline seems to have been effective only among those who experienced side-effects.

Mode of Action of Propantheline.-It has been shown that the $p \mathrm{H}$ of gastric samples depends on the interval since food was last taken and that propantheline, in a dose of $120 \mathrm{mg}$., reduces the number

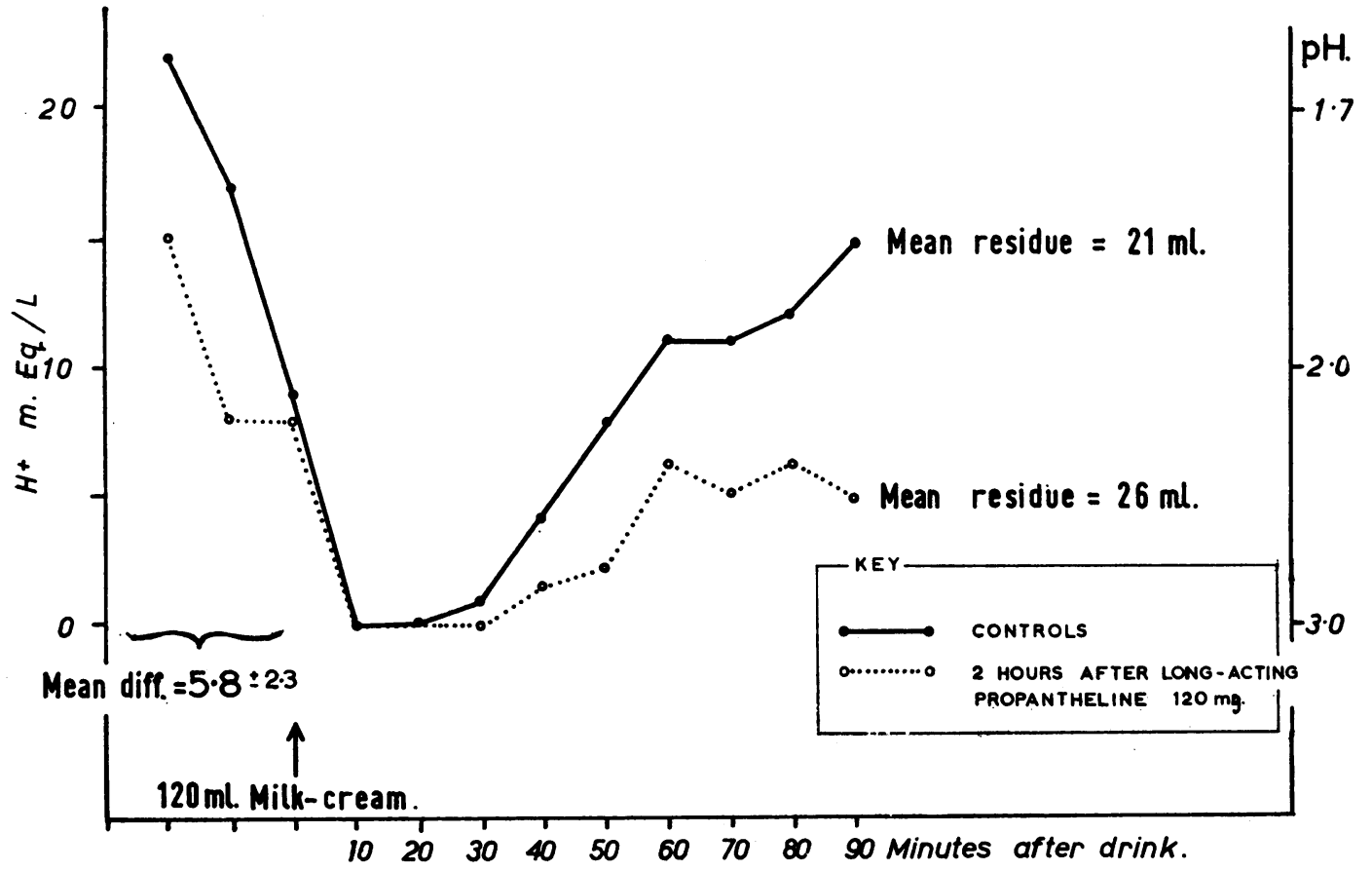

FIG. 6.-The effect of a single dose of long-acting propantheline bromide, $120 \mathrm{mg}$., taken two hours previously, on the $\mathrm{pH}$ of gastric samples before and after a drink of milk-cream. The results shown are the mean of observations on six patients. 
of very acid samples found during a 24-hour observation period. It seems likely that such a drug could influence the $p \mathrm{H}$ of the samples in one or both of two ways. It could delay gastric emptying, so prolonging the buffering action of food, or it could reduce acid secretion. Using the sampling technique, some information about the relative importance of these two actions was obtained (Fig. 6). These curves show the mean acidity in six patients of samples taken at 10-minute intervals after a drink of milk-cream. The subjects were fasting and the stomach was emptied completely at the beginning and end of the experiment. The acidity of samples withdrawn before the drink was significantly $(P=<0.05)$ reduced by propantheline, $120 \mathrm{mg}$., given two hours previously showing that the drug had diminished acid secretion. At the end of the two periods there was no significant difference in the volume of the gastric residue. These findings are not conclusive but suggest that the drug reduced the acidity of samples 30-90 minutes after the drink more by reducing acid secretion than by slowing the rate at which milk left the stomach.

\section{DISCUSSION}

Observations which show that there is a close correlation between the acidity in the stomach and the acidity of samples from the first part of the duodenum (Lopusniak and Berk, 1948; Atkinson and Henley, 1955) indicate the relevance of studies of gastric acidity in patients with duodenal ulcer. The technique of gastric sampling (James and Pickering, 1949) lends itself to a study of any effect which different diets or gastric antisecretory drugs may have on the acidity of gastric contents. Using this technique, several authors have shown that gastric acidity falls after a meal and rises to a maximum before the next meal (Nicol, 1939; Lopusniak and Berk, 1948; Watkinson, 1951). There are several good reasons why many authors who have studied the action of drugs by this technique have used a liquid food (Sun and Shay, 1956; Kasich and Fein, 1958; Kasich and Argyros, 1958; Thomson, 1958). The time of administration, the volume, and the buffering power of a drink can all be accurately determined. The observations in the present study have shown that it is essential to control these particular variables but they have also shown that there is a serious disadvantage in using a liquid food, as the results obtained may give a misleading impression of a drug's effectiveness under more normal conditions. Our results thus provide further evidence in support of the conclusion of Rowlands, Wolff, and Atkinson (1952) that drugs "must be tested under the actual conditions in which they are to be used. . . ."

Remarkably few studies have been made on the action of gastric antisecretory drugs under the conditions in which they might ordinarily be used (Atkinson, 1954; Nicol, 1939; Rowlands et al., 1952). Atkinson demonstrated that a single injection of "banthine" reduced gastric secretion in patients with duodenal ulcer who were fasting; in half of them the aspirate became less acid than $p H$ 3.5 after the drug. Yet when he gave the same drug orally, in the "optimal effective dose", four times daily and combined with large doses of alkali, to patients with duodenal ulcer taking a gastric-type diet, there was no definite reduction of acidity of the gastric contents during the day and a moderate reduction in only three out of five patients at night. In the present study it has been shown that longacting propantheline bromide, given in large doses, slightly reduced the acidity of gastric samples from patients with duodenal ulcer who were taking a bland diet. Whether this reduction was enough to be clinically significant we cannot say, and we can do no more than speculate why the drug was apparently more effective with milk-cream drinks than with diet.

\section{SUMMARY}

The length of time during which food lowers the acidity of the gastric contents is influenced by the quantity and nature of the food. It is therefore necessary to control the diet and the timing of samples when a gastric antisecretory drug is tested by a sampling technique.

The effect of giving a long-acting form of propantheline bromide to patients with duodenal ulcer on a day when they were taking hourly drinks of a milk-cream mixture has been compared with the effect obtained when they were taking a bland diet. There was a greater reduction in acidity with milkcream drinks than with food. It is clear that unless gastric antisecretory drugs are studied under the ordinary conditions of use the results obtained are of doubtful clinical relevance.

We wish to thank Dr. K. E. Harris, Dr. J. C. Hawkesley, Dr. E. E. Pochin, Prof. M. L. Rosenheim, Dr. J. F. Stokes, Dr. D. Taverner, and Prof. R. E. Tunbridge for allowing us to study patients admitted under their care. Dr. E. N. Rowlands introduced us to the sampling technique and we thank him for much advice and help. The staff of the Dietetic Department, University College Hospital, under Miss C. F. Harris, made this study possible by their willing cooperation. We thank Mr. V. K. Asta and Mrs. Prentice for preparing the figures. 


\section{REFERENCES}

Atkinson, M. (1954). Gastroenterology, 26, 288. -, and Henley, K. S. (1955). Clin. Sci., 14, 1 . James, A. H., and Pickering, G. W. (1949). Ibid., 8, 181.

Kasich, A. M., and Argyros, T. G. (1958). Gastroenterology, 34, 232. -, and Fein, H. D. (1958). Amer. J. dig. Dis., 3, 12

Lopusniak, M.S., and Berk, J. E. (1948). Gastroenterology, 11, 891.
Nicol, B. M. (1939).. Lancet, 2, 881

Rowlands, E. N., Wolff, H. H., and Atkinson, M. (1952). Lancet, 2, 1154 .

Sun, D. C. H., Shay, H. (1956). Arch. intern. Med., 97, 442.

, 713 , and Ciminera, J. L. (1955). J. Amer. med. Ass., 158,

Thomson, T. J. (1958), Clin. Sci., 17, 701.

Watkinson, G. (1951). Gastroenterology, 18, 377.

\section{A P P E N D IX}

Standard Diet Used During this Study

6.0 a.m. Weak, milky tea

8.0 a.m. Weak, milky tea

Cornflakes with milk and sugar

1 egg, lightly boiled

3 slices thin bread and butter

Jelly marmalade

10.0 a.m. Milk $5 \mathrm{oz}$.

12.0 noon $2 \mathrm{oz}$. tender mutton

A medium helping of potato, mashed $(2 \mathrm{oz}$.)

A medium helping of sieved carrots $(4 \mathrm{oz}$.)

Pudding: $\frac{1}{2}$ oz. cereal, $7 \mathrm{oz}$. milk, sugar,

1 tablespoon blackcurrant purée

2.0 p.m. Weak, milky tea

4.0 p.m. Weak, milky tea

3 slices of thin bread and butter

Jam

6.0 p.m. Cream of vegetable soup

$2 \mathrm{oz}$. cold breast of chicken

$4 \mathrm{oz}$. mashed potato

8.0 p.m. Milk $5 \mathrm{oz}$. 